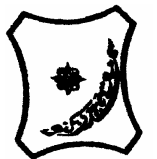

Bayero Journal of Pure and Applied Sciences, 6(1): 127 - 131

Received: September 2012

Accepted: April 2013

ISSN $2006-6996$

\title{
EVALUATION OF CATTLE REARER'S KNOWLEDGE, ATTITUDE AND PRACTICES ABOUT TSETSE FLY IN MURI DISTRICT, TARABA STATE, NIGERIA
}

\author{
*Gumel, M.A., ${ }^{1 *}$ Manu, A.Y. ${ }^{2}$ and Qadeer. M.A. ${ }^{3}$ \\ ${ }^{1}$ Department of Animal Health and Production, Jigawa State College of Agriculture, Hadejia. \\ ${ }^{2}$ Department of Microbiology and Parasitology, Faculty of Medicine, Bayero University, Kano. \\ ${ }^{3}$ National Veterinary Research Zonal Laboratory, Yola, Adamawa State. \\ *Correspondence author: mag37024@yahoo.com
}

\begin{abstract}
A study using a structural questionnaire was conducted in Muri district, Taraba State to evaluate knowledge, attitude and practices of cattle rearers about Tsetse fly (Glossina). Most cattle rearers (94.8\%) had adequate knowledge of Tsetse fly, (69.0\%) gave a local name to it and (100\%) know the effect of Tsetse fly to their cattle. Cattle rearers (52.3\%) reported Tsetse flies transmit disease to cattle, (85.7\%) know where their cattle make contact with the tsetse flies and (67.0\%) know season and period of the day when tsetse flies bite their cattle. $48.1 \%$ recognized tsetse fly as an important threat to their cattle, (90.0\%) reported their herd had contact with tsetse flies in the preceding 12 months, (90.9\%) practices preventive measures against tsetse flies, and only (9.1\%) do not. Respondents had high knowledge of tsetse fly and the economic significance attributed to cattle and the use of pour- on in the control of tsetse fly in the districts should bee raised among cattle rearers. Results obtained from this study could be used in the formulation of extension material in trypanosomosis prevention.
\end{abstract}

Keywords: Knowledge, attitude, practice, tsetse fly (Glossina) trypanotolerant, Taraba, Muri.

INTRODUCTION

Tsetse flies are some group of biting flies that are distributed over 10 million square kilometers of Africa and are extremely significant as biological vector of African animal trypanasomosis and sleeping sickness in humans (Urquahart et al., 1996). Currently in Nigeria, studies have shown the wide distribution of economically important Glossina spp in all states of the federation including the federal capital territory Onyiah, (1985). The area infested by tsetse species extend from latitude $4^{\circ} \mathrm{N}$ (Atlantic coast) to approximately $13 \mathrm{~N}^{\circ}$ with northern extensions along Hadejia - Jama'are river valley.

African animal trypanosomoses are serious diseases of livestock in many parts of the tropics and subtropics. The disease is caused by trypanosomes which live in the blood and some tissue of their host (man, cattle, pig, horses, rabbit, goat etc) (Ikede, 1989), also the disease is considered to be a major constrain to livestock industry and food security in sub-Saharan Africa (Swallow, 2000). An estimated direct loss in meat and milk yield as well as cost of disease control amounting to the tune of $\$ 600$ million to $\$ 1.2$ billion annually on the global scale (FAO, 1994). Losses to trypanosomosis in Nigeria was estimated at N135 million annually Esuruoso, (1973).

In man, the African human trypanosomosis or sleeping sickness due to Trypanosome brucie gambiense is a debitating and complex disease.

The disease at the chronic stage, results in a major disruption of the circadian rythmicity of sleep and wakefulness (Radomski et al., 1995). Of the twenty two species of Glossina that are identified in Africa, eleven infest $75 \%$ of Nigeria landmass and four play a very significant role in the transmission of African animal trypanosomosis viz Glossina submorsitans, $G$. Palpalis and G. longipalpis.

The presence of tsetse exclude livestock from large area of considerable agricultural potential by virtue of the severity of the diseases caused by tsetse transmitted trypanosomes. It has been postulated that livestock population could be doubled if tsetse and trypanosomosis are controlled or eradicated in Nigeria. Furthermore, it has been predicted that, if trypanosomosis is controlled or eradicated, tsetse infested areas of the country could support additional 2.5 to 3.2 times the current estimated livestock population (Ikede, 1989).

African animal trypanosomosis (AAT) is managed through vector control; keeping trypanotolerant cattle and the used of trypanocidal drugs by way of chemotherapy and chemoprophylaxis (Urquahart et al., 1996).

In Africa and especially Nigeria, trypanosomosis control facilities have become dysfunctional (Njoku et al., 2003) and the advent of veterinary services privatization had let the responsibility for diagnosis, treatment and prevention of this notorious disease to lie almost entirely in the hands of cattle rearer's and quarks who are untrained and unskilled, through chemotherapy and chemoprophylaxis with trypanocidal agents. Muri district provide a significant grazing ground for nomadic cattle which as well serves as habitat for some savannah tsetse fly species, the vector of notorious African animal trypanosomosis (Daniel et al., 1993). In view of the above, this study was conceived in order to determine level of knowledge, attitude and practices towards tsetse management and control by cattle rearers in the course of prevention of devastating trypanosomosis in the district. 
Results obtained from this study can be used in the formulation of extension material in the trypanosomosis prevention.

\section{MATERIALS AND METHODS \\ Study Area}

The study area is located in Muri district of Taraba State which lies between latitude $8^{\circ} 13^{\prime} \mathrm{E}$ and $9^{\circ} 14^{\circ} \mathrm{N}$ and longitude $10^{\circ} 97^{\prime}$ and $10^{\circ} 30^{\prime} \mathrm{E}$. The climate is tropical and vegetation terrain fall within Guinea savannah ecological zone characterized by short grasses interspersed with tall trees (Taraba State Government Diary, 2008).

\section{Administration of Questionnaires}

Knowledge, attitude and practice (KAP) interviewer administered questionnaire (in English) was developed after preliminary interaction with cattle rearers. It was then administered in four cattle markets selected by simple random sampling procedure in Muri district to assess knowledge, attitude and practice in respect of tsetse fly (Kinunghi et al., 2006). Pretest was conducted with twenty copies to ensure questions were comprehensible and acceptable. Questionnaires were administered by the researcher, veterinary assistant and veterinary drug vendors. The questionnaires were administered in local language (the administrator translating the questions and responses). Six photographs of different insects were presented to the respondents to identify amongst which is tsetse fly in order to ascertain knowledge. Seventy seven out of one hundred questionnaires were retrieved from the respondents.

\section{Analysis of Data}

All data collected through the questionnaire were analyzed using frequency tables and percentages, measures of control tendency and chi-square (Balogun and Owoje, 2005).

\section{RESULTS}

\section{Participant Characteristics}

The result of the analysis (Table 1 ) shows that majority of the respondents $22(28.6 \%)$ fall within age group of 31.40 years with mean age 30 years and only $16(20.8 \%$ were above sixty years old. The percentage of males and females respondents are 68 $(88.3 \%)$ and $9(11.7 \%)$ respectively. Table 2 revealed that $73(95.8 \%)$ of the respondents know tsetse fly and $69(89.6 \%)$ of them were able to give its local name. Table 3 shows that, all respondents 77 (100\%) acknowledged that tsetse fly bite and 40 (52\%) agreed that, the bite of tsetse fly can cause disease. Also from table 3, $20(26 \%)$ of the respondents agreed, tsetse fly bite cause annoyance to the host and $10(13 \%)$ believed the bite cause distraction during grazing activities. Table 4 indicated that, 48 $(62.8 \%)$ of the respondents believed that their herd have contact with tsetse flies, at forest; $14(18.2 \%)$ at Riverine areas and $11(14.3 \%)$ at open space or unforested area. Only $11(14.3 \%)$ do not know where their herds make contact with tsetse flies. From table $5, \quad 41(53.2 \%) ; 9(11.7 \%)$ and $17(22.1 \%)$ of the respondents believed tsetse fly bite during dry; rainy season and all year round respectively. Only 10 $(13.0 \%)$ do not know the specific season which tsetse fly bite. Also in table 5, 34 (44.0\%) of the respondents reported tsetse fly bite in the afternoon during grazing while $2(2.3 \%)$ believed tsetse fly bite in the morning hours. From the same table, $24(31.2 \%)$ and 8 $(10.0 \%)$ of the respondents acknowledged tsetse fly bite cattle all day round and at night respectively. Table 6 shows that $64(88.1 \%)$ of the respondents recognized the importance of tsetse fly as a threat to livestock and man and $54(90.0 \%)$ of the respondents herds had contact with tsetse fly the preceding year. The same table indicated $23(42.6 \%), 25$ (46.3\%), 6 $(11.1 \%)$ and $2(3.7 \%)$ of the respondents acknowledged contact with tsetse fly at riverside, forest and grazing farm land respectively. Table 7 showed that $70(90.9 \%)$ of the respondents practice tsetse fly bite prevention in their herds while 7 $(10.0 \%)$ do not. Also from this table, 49 (63.6\%) of the respondents use insecticides while 21 (27.3\%) employ traditional preventive measures against tsetse fly. The result also revealed that, those respondents that engaged in tsetse fly bite prevention, 70 (90.9\%) of the respondents avoid their cattle from making contact with tsetse fly habitat and $54(77.1 \%), 21$ $(30 \%)$ use traditional smoking of herd and herd spray with insecticides respectively. However, 8 (11.4\%) use pour-on to repel tsetse fly while none of the respondents employ keeping trypanotolerant cattle as a means of control. From table 7 also, 54 (77\%) of the respondents engaged in tsetse fly control in rainy season while $25(35.7 \%)$ carryout the control in dry season but only $15(21.4 \%)$ does both seasons.

Table 1: Biodata of respondents in Muri district

\begin{tabular}{lll}
\hline Age Years & $(\mathbf{N})$ & \% \\
\hline Below & 11 & 14.3 \\
$31-40$ & 22 & 28.6 \\
$41-50$ & 12 & 15.6 \\
$51-60$ & 16 & 20.8 \\
Above 60 & 1 & 20.8 \\
Total & 77 & 100 \\
Gender & & \\
Male & 68 & 88.3 \\
Female & 9 & 11.7 \\
\hline
\end{tabular}


Table 2: Evaluation of knowledge of Tsetse fly in Muri district

\begin{tabular}{lll}
\hline Knowledge $\mathbf{N}=\mathbf{7 7}$ & $\mathbf{( N )}$ & \% \\
\hline Do you know tsetse fly & 73 & 94.8 \\
If yes, give local name & & \\
Local name & & 44.2 \\
Nyabbare/Nyabbel yami/yabe & 34 & 22.1 \\
Bubi/Bubi lande/wadube & 17 & 2.6 \\
Bakkare & 2 & 16.9 \\
Kudan tsando/Tsando & 13 & 1.3 \\
Loe & 1 & 1.3 \\
Goteze & 1 & 1.3 \\
Kondozi & 1 & 10.4 \\
Do not know & 8 & \\
\hline
\end{tabular}

Table 3: Evaluation of responses by respondents on effect of tsetse fly on livestock

\begin{tabular}{lll}
\hline Effect $\mathbf{N}=\mathbf{7 7}$ & $\mathbf{( N )}$ & $\mathbf{\%}$ \\
\hline Bite & 77 & 100 \\
Nuisance & 20 & 26 \\
Distract grazing activities & 10 & 13 \\
Transmit disease & 40 & 52 \\
Any two of the above & 4 & 5 \\
None of the above & 3 & 3.9 \\
Name disease transmitted by tsetse fly to & & \\
livestock & 39 & 50.6 \\
a) Samore & 4 & 5.2 \\
b) Jola & 6 & 7.8 \\
c) Kenye & 2 & 2.6 \\
d) Nyaububi & 3 & 3.9 \\
e) Hanta & 12 & 15.6 \\
f) Trypanosomosis & 11 & 14.3 \\
g) Do not know & & \\
\hline
\end{tabular}

Table 4: Evaluation of responses on livestock site of contact with Tsetse fly

\begin{tabular}{lll}
\hline Location $\quad \mathbf{N = 7 7}$ & $\mathbf{( N )}$ & \% \\
\hline Forest & 48 & 62.3 \\
Riverine area & 14 & 18.2 \\
Unforested areas & 4 & 5.2 \\
Do not know & 11 & 14.3 \\
\hline
\end{tabular}

Table 5: Evaluation of respondents on season and period of the day when Tsetse fly bites

\begin{tabular}{lll}
\hline Effect N $\mathbf{N 7}$ & $\mathbf{( N )}$ & \% \\
\hline Season & & \\
Dry season & 41 & 53.2 \\
Rainy season & 9 & 11.7 \\
Both seasons & 17 & 20.1 \\
Do not know & 10 & 13.0 \\
Period of the day & & \\
Morning & 2 & 2.3 \\
Afternoon & 34 & 44.0 \\
Evening & 9 & 10 \\
Night & 8 & 10.0 \\
Day and night & 24 & 31.2 \\
\hline
\end{tabular}

Table 6: Evaluation of respondents' attitude towards tsetse fly

\begin{tabular}{lll}
\hline Perception & $\mathbf{N}=\mathbf{7 7}$ & $\mathbf{\%}$ \\
\hline $\begin{array}{l}\text { Recognition of Tsetse fly as important threat to } \\
\text { livestock }\end{array}$ & 64 & 88.1 \\
$\begin{array}{l}\text { Herd had control with tsetse in the preceding } 12 \\
\text { months }\end{array}$ & 54 & 90.0 \\
$\begin{array}{l}\text { Location of contact with tsetse fly } \\
\text { a) River side }\end{array}$ & $\mathrm{N}=54$ & \\
b) Forest & 23 & 42.6 \\
c) Grazing farm land & 25 & 46.3 \\
\hline
\end{tabular}


Table 7: Practices of respondents towards Tsetse fly prevention

\begin{tabular}{|c|c|c|}
\hline Effect $\mathbf{N}=77$ & (N) & $\%$ \\
\hline Prevention of tsetse fly & 70 & 90.9 \\
\hline Apply traditional method & 21 & 27.3 \\
\hline Apply insecticides & 49 & 63.6 \\
\hline None & 7 & 9.1 \\
\hline Type of prevention $(\mathrm{N}=70)$ & & \\
\hline $\begin{array}{l}\text { Prevent herd - tsetse fly contact through } \\
\text { voidance of tsetse ecology }\end{array}$ & 70 & 100.0 \\
\hline $\begin{array}{l}\text { Use traditional herbs to smoke herd thus } \\
\text { repelling tsetse fly }\end{array}$ & 54 & 77.1 \\
\hline Spray of hers with insecticides & 21 & 30.0 \\
\hline Use of pour-on to repel tsetse fly & 8 & 11.4 \\
\hline $\begin{array}{l}\text { Keeping of trypanotolerant cattle seasons of } \\
\text { practice }\end{array}$ & 0 & 0 \\
\hline Rainy season & 54 & 77.1 \\
\hline Dry season & 25 & 35.7 \\
\hline Rainy and dry seasons & 15 & 21.4 \\
\hline
\end{tabular}

\section{DISCUSSION}

Table 1 shows that majority $22(28.6 \%)$ of the respondents are between the ages of $31-40$ years and only $26(20.8 \%)$ are above 60 years. This shows that most of the respondents are within their energetic and productive ages who can perform well and impart to new generation of cattle rears new skills of animal disease and parasites prevention. The table also indicates $68(88.3 \%)$ of the respondents were males while $9(11.7 \%)$ were females.

\section{Respondents Knowledge of Tsetse Fly}

It was discovered from the findings that majority of the respondents have high knowledge

$(94.8 \%)$ of tsetse fly and how it is called locally. Similar observation was made in Nigeria by Njoku et al., (2003) and Ohaga et al., (2007) in Kenya. This could be as a result of the economic importance associated with the disease agent which tsetse transmits biologically (Trypanosomosis).

Table 2 indicated all respondents 77 (100\%) agree tsetse fly bite cattle and only $40(52 \%)$ believed the bite cause disease to their cattle. This observation indicates average awareness of the respondents on the role play by tsetse on disease transmission among cattle. A similar observation was made in Kenya in agro-pastoral communities in Lambwe and Kwale (Olubai et al., 1995). From the table also, 66 (85.7\%) were able to give a name to the disease tsetse flies transmit to their cattle.

From table 3, all respondents 77 (100\%) knows tsetse fly bite has effect on the host. This result tally with knowledge of tsetse fly and it indicates high level of awareness of tsetse fly and the effects it produces. This table also indicates 20 (26\%), 10 (13\%), 40 $(52 \%)$ and $40(52 \%)$ believed tsetse fly cause nuisance, district grazing activities, transmit disease and any two mentioned to cattle respectively. Only 3 (3.9\%) did not mentioned effects of tsetse fly on cattle. The result also indiated that $11(14.3 \%)$ of the respondents were not able to give a name to the disease tsetse fly transmit to cattle however 39
$(50.6 \%), 4(5.2 \%), 6(7.8 \%), 2(2.6 \%), 3(3.9)$ and 12 (15.6\%) mentioned Samore, Jola, Kenya, Nyaububi, Hanta and trypanosomosis respectively as the names of disease transmitted to cattle by tsetse flies. This indicates also high level of awareness of the tsetse fly and the disease cause to the cattle by the respondents. A similar observation was made in study by Onyiah, (1997).

Table 4 depicted, 48 (62.3\%), $14(18.2 \%)$ and 4 $(5.2 \%)$ believed that host-vector contact occur at forest, reverine area, and unforested area respectively. Only $11(14.3 \%)$ do not know where cattle contact tsetse fly. This result shows majority of the respondents have knowledge of where a cattle makes contact with tsetse flies. This could be the reasons why some of the respondents avoid tsetse fly habitat as a means of prevention of bovine trypanosomosis. A similar study in Nigeria (Njoku et al., 2003) showed that, farmers believed that African animal trypanosomosis is caused by fresh water stream.

Table 5 indicate 41 (53.2\%) of the respondents believed that tsetse fly bite their cattle during dry season and $9(11.7 \%)$ believed their cattle are bitten by tsetse fly in the rainy season. Their believe could be associated to the fact, cattle rearers take their cattle for grazing and watering in tsetse fly ecology in dry season in that is only the point where their cattle can get grasses and water. The attitude of respondents towards tsetse is good and positive as depicted in Table $6.64(88.1 \%)$ of the respondents recognized the importance of tsetse flies and 84 $(90.0 \%)$ of the respondents herds had contact with tsetse fly in the preceding 12 months.

The practices of respondents towards tsetse flies are also very good in that in Table 7, 70 (90.9\%) of them practice one or the other form of tsetse fly control. Their attitude followed the good knowledge of tsetse fly. However, an exceptionally wide gap between the uses of insecticide spray and pour-on exist in the control of tsetse fly by the respondents. 
A similar observation was reported by Magana et al., (2004) in Uganda and Ohaga et al., (2002) in Kenya. Table 7 also depicted that, control of tsetse through keeping trypanotolerant cattle is not practiced by respondents in Muri district. It also showed that 54 $(77 \%), 25(35.7 \%)$ of the respondents practice prevention in rainy and dry seasons respectively while $15(21.4 \%)$ of them practice tsetse control throughout the seasons.

\section{CONCLUSION AND RECOMMENDATIONS}

From the results of this study, respondents have high knowledge of Tsetse fly and the economic importance associated to cattle production. Their attitudes and practices towards Tsetse flies are also good but their

\section{REFERENCES}

Balogun, M.O. and Owoje, E.T. (2005). Knowledge and Practices of Breast Self Examination among Female Traders in Ibadan, Nigeria Annals of Ibadan Postgraduate Medicine, (3)(2): $52-55$.

Daniel, A.D., Dadal, A.J., Kalajaiye, J.O. and Dalhatu, A.D. (1993). Prevalence of Bovine Trypanosomosis in Gongoal State of Northern Nigeria. Rev. Elev. Med. Ray. Trop. 46(4): 511-574.

Esuruoso, G.o. (1973). The Epizootiology, Prevalence and Economic Aspects of Bovine Trypanosomiasis in Nigeria. In: Proc. $7^{\text {th }}$ Annu. Health Assoc. Missouri, USA, October 13 - 19, P. $160-174$.

FAO, (1974). Programme for the Control of African Animal Trypanosomosis. Food and Agriculture Organization of the United Nations, Rome.

Ikede, B.O. (1989). Control of Animal Trypanosomosis as a Strategy for increased Livestock Production. Proc. Preparatory Workshop, Vom, 5 - 9. 1989.

Kinunghi, S.N., Malele, I.I., Kiboma, S.N., Malemba, L.E., Sahani, J.K. (2006). Knowledge, Attitudes and Practices on Tsetse and Sleeping Sickness among Communities Living in and around Serengeti National Park, Tanzania. Tanz. Health Res. Bull 8(3). 168 172.

Magona, J.W., Walubengo, J., Olaho - Mukani, W. (2004). Knowledge and Attitudes of Cattle Owners Regarding Trypanosomosis Control in Tsetse fly Infested Areas of Uganda. J.S. Afri. Vet. Assoc. 75(4), $173-176$.

Njoku, C.I., Uzoigue, N.R., Afaghoma, V.N., Abubakar, A. and Usman, B. (2003). Community Perception of Animal Trypanosomosis in practice of keeping trypanotolerant cattle and use of pour-on in the control of Tsetse and trypanosomosis is poor.

In view of the above, it was recommendations that: Awareness on keeping trypanotolerant cattle by cattle rearers in the district should be raised.

The use of pour-on on the prevention of Tsetse fly and other external parasites (arthropod) should be excited among cattle rearers to the district. This is because, pour - on is easier to use and also control other external parasites of Ticki, lice etc.

Research should be encourage to investigate the local herbs used by cattle rearers to repel or control Tsetse fly to save cost and hazard associated with the use of conventional insecticides.

Durbi village, Jos East Local Government Area of Plateau State, Central Nigeria. In: Proceedings of the 27th Meeting of the ISC TRC, Pretoria, South Africa. Pp. $199-204$.

Ohaga, S.O., Kokwaro, E.D., Ndiege, I.O., Hassanali, A. and Saini, R.K. (2007). Livestock Farms' Perception and Epidemiology of Bovine Trypanosomosis in Kwale District, Kenya. Preventive Veterinary Medicine: 80(1): 24 33.

Olubai, W.A., Eschessah, D.N. and Opiyo, E.A. (1995). Assessment of Gross Community Perception of Tsetse Fly, Human and Criminal Trypanosomosis in the Lambue Valley, Kenya. In: Proceedings of the $23^{\text {rd }}$ Meeting of the ISCTRC, Banjul, the Gambia. Pp. 112 123.

Onyiah, J.A. (1985). Tsetse Distribution in Nigeria in NITR Annual Report, 1980 - 1983. NITR, 1985. Pp. $28-32$.

Onyiah, J.A. (1997). African Animal Trypanosomosis: An Overview of the Current Status in Nigeria. Trop. Vet. 15: $111-116$.

RadomskI, N.W., Buguct, A., Moritmayeur, A., Bugui, P., Bonddon, L., Dona, F., Lonsdrfer, A., Taple, P. and Dumas, M. (1995). 24 Hours Plasma Cortisol Prolactin in Human African Trypanosomosis Patients and Healthy African Controls. Am. J. Trop. Med. Hyg. 52: 281 286.

Swallow, B.M. (2000). Impact of Trypanosomosis on Agriculture: PAAT Technical Scientific Series 2: $35-38$.

Taraba State Government Diary, (2008). Taraba State Official Diary, Government Printer Jalingo, Nigeria. Pp. 25 - 29.

Urquahart, G.N., Amour, J. Duncan, J.I., Lennings, F.W. (1996). Veterinary Parasitology. Second ed. Blackwell Publishing, 289. Pg. $157-158$. 